\title{
Autistic traits and mental health in women with the fragile-X premutation: maternal status versus genetic risk
}

Sarah J. White, Denise Gerber, Romina D. Sanchez Hernandez, Anthonia Efiannayi, Ishita Chowdhury, Hannah Partington and Joanna F. Moss

\section{Background}

Research on women with the fragile-X premutation (FX-p) has been underrepresented within the field of behavioural phenotypes.

\section{Aims}

To understand whether the FX-p confers risk for autistic traits, depression and anxiety, independent of maternal status.

\section{Method}

In study 1, mothers of children with fragile-X syndrome (M-FXp; $n=51$, mean age 43 years $(s . d .=5.80))$ were compared with mothers of autistic children (M-ASD; $n=59$, mean age 42 (s.d. = 5.80)), mothers of children with Smith-Magenis syndrome (MSMS; $n=27$, mean age 39 (s.d. $=7.20)$ ) and mothers of typically developing children (M-TD; $n=44$, mean age $40($ s.d. $=4.90)$ ). In study 2, the M-FXp group were compared with non-mothers with the FX-p (NM-FXp; $n=17$, mean age 32 (s.d. =9.20)), typically developed non-mothers (NM-TD; $n=28$, mean age 31 (s.d. = 6.80)) and the M-TD group. All participants completed an online survey, including measures of IQ, autistic traits, anxiety, depression and positive affect.

\section{Results}

In study 1: the M-FXp group reported more autistic traits than the $\mathrm{M}$-TD group $\left(P<0.05, \eta^{2}=0.046\right)$. Anxiety and parental stress were elevated in the M-FXp, M-SMS and M-ASD groups relative to the M-TD group (all $P \leq 0.003, \eta^{2}=0.079-0.322$ ). In study 2: a main effect of premutation status indicated that women with the FX-p report elevated autistic traits and anxiety $(P \leq 0.007$ $\left.\eta^{2}=0.055-0.060\right)$; this did not interact with maternal status.

\section{Conclusions}

The findings indicate that women with the FX-p show an increased risk for autistic traits and anxiety. This risk is specific to the presence of the FX-p and is not fully accounted for by maternal status or the stress of caring for children with neurodevelopmental disorders.

\section{Keywords}

fragile-X premutation; broader autism phenotype; autistic characteristics; anxiety; depression.

\section{Copyright and usage}

(C) The Author(s), 2020. Published by Cambridge University Press on behalf of the Royal College of Psychiatrists. This is an Open Access article, distributed under the terms of the creative Commons Attribution licence (http://creativecommons.org/ licenses/by/4.0/), which permits unrestricted re-use, distribution, and reproduction in any medium, provided the original work is properly cited.

\section{Background}

Fragile-X syndrome (FXS) is the most common cause of inherited intellectual disability and the most common identifiable cause of autism. $^{1,2}$ Instigated by an expansion of a trinucleotide (CGG) repeat on the FMR1 gene of the X chromosome, FXS results in reduced production of the FMRP protein. Fragile-X premutation carriers (FX-p) have an expansion of between 55 and 200 CGG repeats on the FMR1 gene. The premutation is relatively common within the general population with approximately 1 in 151 women and 1 in 468 men being affected. ${ }^{3}$

Individuals with the FX-p are generally considered to be cognitively unaffected, although mild difficulties in executive function, working memory and information processing skills have been described. ${ }^{4}$ Recent literature strongly indicates that the FX-p is also a risk marker for autistic traits and negative mental health outcomes. ${ }^{5-11}$ This risk is evident prior to having a child with FXS. ${ }^{12,13}$ Although negative mental health outcomes are thought to be the most common challenges faced by individuals with the FX-p, ${ }^{14}$ research to date has focused primarily on associated physical conditions. To improve awareness of mental health challenges faced by individuals with the FX-p, Hagerman and colleagues ${ }^{14}$ proposed the term fragile $\mathrm{X}$-associated neuropsychiatric disorders. This term was supported and adopted by the European Fragile $\mathrm{X}$ Network in $2020 .{ }^{15}$ Greater understanding of these associated conditions is now critical to ensure appropriate and targeted support for individuals with the FX-p and their families.

\section{Fragile-X-associated neuropsychiatric conditions}

Women with the FX-p present with a complex set of risk factors that are likely to interact with one another to mediate heightened vulnerability for mental health problems. The most obvious risk factor is the stress associated with caring for a child or children with intellectual disability, here specifically FXS - as all mothers of a child with FXS will have the FX-p. Elevated levels of stress and affective disorder are well documented within the broader intellectual disability and neurodevelopmental disorder literature. ${ }^{16}$ Further, studies have reported that mothers of children with FXS show more signs of compromised psychological well-being than mothers of children with Down syndrome ${ }^{17}$ and a strong association between child behaviour and maternal stress and depression has been found in this population. ${ }^{18}$ The way in which the elevated autistic traits in mothers with the FX-p might also contribute to, and interact with, this risk pathway is not known.

\section{Aims}

Our aims in this study were:

(a) to delineate the behavioural and neuropsychiatric profile of individuals with the FX-p (studies 1 and 2);

(b) to evaluate the role of genetics versus environment on the presentation of autistic characteristics and mental health challenges in women with the FX-p (study 1); and 
(c) to consider how maternal status interacts with the FX-p to confer risk for autistic traits and symptoms of anxiety and depression (study 2).

\section{Method}

\section{Study 1: Autistic traits, anxiety and depression in mothers of children with FXS, Smith-Magenis syndrome and autistic children}

Recruitment

Mothers of children with FXS, with the FX-p themselves (M-FXp group), were recruited through the Fragile X Society, UK; an email inviting women to participate was sent to approximately 700 individuals on the Fragile $\mathrm{X}$ Society research database. Mothers of autistic children with no identified genetic aetiology (M-ASD group) were recruited through six branches of the National Autistic Society around London and Birmingham, UK, via email, Twitter, Facebook or newsletter. Mothers of children with Smith-Magenis syndrome (caused by a de novo genetic mutation; M-SMS group) were recruited through the Smith-Magenis Syndrome Foundation, UK, via email or at support group conferences in the UK. Mothers of typically developing children (M-TD group) were recruited through eight mainstream schools around London, UK, via email, Twitter, Facebook or newsletter.

All participants were required to be 50 years old or younger and to have at least one child with the relevant diagnosis. Mothers in the M-TD group were included if they did not report having a child with a diagnosis of a developmental disorder. All mothers in the M-FXp group confirmed that they were carriers of the FX-p themselves.

Six participants (two in the M-ASD group, three in the M-TD group and one in the M-SMS group) did not complete the measures of mental health and parental stress. These participants were retained in the sample for analyses not considering these variables. In addition, ten participants did not complete the IQ test but were retained in the sample. Finally, two participants were excluded from the M-TD group as they had a child with a diagnosis of dyslexia; two were excluded from the M-ASD group as their child also had a genetic syndrome; and two were excluded from the M-SMS group who had a second child with an autism diagnosis. We also chose to retain one participant in the M-FXp group whose child had the FX-p rather than the full syndrome.

\section{Participants in study 1}

Participant characteristics are shown in Table 1. In total, there were 51 women in the M-FXp group, 59 in the M-ASD group, 27 in the M-SMS group and 44 in the M-TD group who were included in the present study. The groups were comparable for IQ $(H(3)=3.671$, $P=0.271)$ but did differ in age $(H(3)=12.852, P=0.005)$, with the M-FXp group being significantly older than the M-TD $(P=0.013)$ and M-SMS groups $(P=0.043)$. There was also a significant group difference in education qualifications $\left(\chi^{2}(3)=12.974, P=0.005\right)$; the
M-TD group were more likely to have a higher education qualification than the M-FXp $(P<0.05)$ and M-SMS groups $(P<0.05)$. Further, there was a significant group difference in household income $\left(\chi^{2}(3)=\right.$ 10.976, $P=0.012)$; more participants in the M-TD group earned above $£ 45000$ per year than those in the M-FXp group $(P<0.05)$.

\section{Procedures}

The authors assert that all procedures contributing to this work comply with the ethical standards of the relevant national and institutional committees on human experimentation and with the Helsinki Declaration of 1975, as revised in 2008. All procedures involving human subjects/patients were approved by the University of Birmingham ethics committee (ref: ERN_12-0018P). Data collection took place through an online survey created in Limesurvey. ${ }^{19}$ Written informed consent was obtained from all participants.

\section{Measures}

Autism Spectrum Quotient: The Autism Spectrum Quotient $(\mathrm{AQ})^{20}$ was used to assess behavioural traits associated with autism. Participants responded to a series of 50 statements asking about a range of abilities and preferences relating to social skills, attention switching, attention to detail, communication and imagination. The AQ has previously been used with mothers of children with ASD. $^{21}$

Hospital Anxiety and Depression Scale: The Hospital Anxiety and Depression Scale (HADS) ${ }^{22}$ assesses emotional traits relating to depression and anxiety. Participants responded to 14 items about the degree to which they experienced various emotional states. The HADS can be used as a screening tool and has previously been used with parents of children with neurodevelopmental disorders. ${ }^{23} \mathrm{~A}$ total HADS score is calculated comprised of two subscales: anxiety and depression.

\section{Questionnaire on Resources and Stress - Friedrich short}

form: The Questionnaire on Resources and Stress - Friedrich short form $(\mathrm{QRS}-\mathrm{F})^{24}$ is a questionnaire designed to measure stress in families that include a family member with a disability. ${ }^{25}$ Only the 'Parent and the Family problems' subscale was used in the current study because of its focus on the impact on parents of having a child with a disability. Participants responded to seven true/false statements. The QRS-F has successfully been used with parents of children with various neurodevelopmental disorders including ASD. ${ }^{23}$

Positive Gain Scale: The Positive Gain Scale (PGS) ${ }^{26}$ evaluates the positive aspects of caring for a child with a disability; this was not completed by the M-TD group. Participants responded to seven items measuring the degree to which they felt their child's disability had benefited them positively, such as affecting their character or

Table 1 Study 1 participant characteristics: chronological age, IQ, education and household income

\begin{tabular}{|c|c|c|c|c|}
\hline & $\begin{array}{c}\text { M-FXp group } \\
\quad(n=51)\end{array}$ & $\begin{array}{c}\text { M-ASD group } \\
\quad(n=59)\end{array}$ & $\begin{array}{l}\text { M-SMS group } \\
(n=27)\end{array}$ & $\begin{array}{l}\text { M-TD group } \\
\quad(n=44)\end{array}$ \\
\hline Age, years: mean (s.d.) & $43(5.8)$ & $42(5.8)$ & $39(7.2)$ & $40(4.9)$ \\
\hline $\mathrm{IQ}^{\mathrm{a}}$ mean (s.d.) & $116(18.1)$ & $123(18.3)$ & $121(18.1)$ & $121(15.4)$ \\
\hline Education, \% higher education $(n)$ & $59(30)$ & $69(41)$ & $63(17)$ & $91(40)$ \\
\hline Household income, $\%$ above $£ 45000$ per annum (n) & $46(21)$ & $62(36)$ & $48(11)$ & $78(32)$ \\
\hline \multicolumn{5}{|c|}{$\begin{array}{l}\text { M-FXp, mothers of children with fragile- } x \text { syndrome, with the fragile-x permutation themselves; M-ASD, mothers of autistic children; M-SMS, mothers of children with Smith-Magenis } \\
\text { syndrome; M-TD, mothers of typically developing children. } \\
\text { a. Missing IQ data: } n=4 \text { M-ASD group, } n=1 \text { M-SMS group, } n=5 \text { M-TD group. } \\
\text { b. Household income data not declared: } n=5 \text { M-FXp group, } n=1 \text { M-ASD group, } n=4 \text { M-SMS, } n=3 \text { M-TD group. }\end{array}$} \\
\hline
\end{tabular}


knowledge. The PGS has been effectively used with mothers of children with various neurodevelopmental disorders. ${ }^{23}$

The Positive Affect Scale: The Positive Affect Scale (PAS) ${ }^{27}$ measures the positive dimension of mood; here, participants responded to only five of the ten original items, regarding the extent to which they had experienced certain feelings and emotions in the past week. This shortened version of the PAS has been successfully used with mothers of children with a range of neurodevelopmental disorders. ${ }^{23}$

Culture Fair Intelligence Test: The Culture Fair Intelligence Test $(\mathrm{CFIT})^{28}$ is a non-verbal reasoning skills test that was used as a rough estimate of IQ. Scale 2 form A subtests 1 and 3 were used in an online format; participants were given $3 \mathrm{~min}$ for each subtest. This short version has similar psychometric properties to the full version.

\section{Study 2: the influence of maternal status on autistic traits and mental health in women with FX-p}

Measures, procedures and ethical approval for study 2 are the same as those outlined in study 1 with the exception that both the QRS-F and the PGS were excluded from study 2 as these measures are specific to parental responsibilities.

\section{Design and recruitment}

This is a 2 (diagnosis) $\times 2$ (motherhood) design. Data collected from mothers (M-FXp and M-TD) were taken from study 1 and additional data were collected from two further groups. Women with the FX-p with no children (NM-FXp) were recruited via email through the Fragile X Society research database and through leaflets/advertisements posted on social media sites. Women with no children and no known genetic syndrome themselves (NM-TD) were recruited through adult further education colleges, evening university courses attracting mature students and adverts in the local community. All participants were required to be between 18 and 50 years old and all participants completed all the questionnaires. All participants in the NM-FXp group confirmed that they were carriers of the FX-p themselves and had been diagnosed following DNA analysis. One respondent was excluded because she reported having a full fragile-X mutation.

\section{Participants in study 2}

Participant characteristics are shown in Table 2. In addition to the 51 individuals in the M-FXp group and 44 in the M-TD group, there were 17 participants in the NM-FXp group and 28 in the NM-TD group who were included in study 2 . The groups were broadly comparable for age and IQ except that, as expected, mothers were older than non-mothers $(F(3,136)=69.41, P<$ $0.001)$. There was a significant group difference in level of education qualifications $\left(\chi^{2}(3)=26.92, P<0.001\right)$; the $\mathrm{M}$-TD group was more likely $(P \leq 0.005)$ and the NM-FXp group was less likely $(P \leq 0.01)$ to have a higher education qualification than all other groups. Further, there was a significant group difference in household income $\left(\chi^{2}(3)=23.79, P<0.001\right)$; more M-TD participants earned above $£ 45000$ per year compared with all other groups $(P<0.001)$.

\section{Results}

\section{Study 1 results}

Although a number of variables in each group were not normally distributed, parametric statistical analyses were employed. The parametric tests used (one-way ANCOVAs and stepwise multiple linear regressions) are robust to small deviations in normality ${ }^{29}$ and parametric tests enabled statistical control for participant characteristics that significantly differed between the groups (age, education and household income). An alpha level of 0.05 was used throughout, with the exception of post hoc analyses and analysis of subscale scores, when alpha was set at 0.01 due to the multiple comparisons conducted. Group means, standard deviations and \% meeting cut-off scores on all measures are given in Table 3.

\section{Autistic traits in study 1}

The groups differed in AQ total score $(F(3,173)=2.759 ; P=0.044$; $\left.\eta^{2}=0.046\right)$, with the M-FXp group reporting significantly more autistic traits than the M-TD group $(P=0.010)$. Although, not significant, there was a trend for the M-ASD group to report more autistic traits than the M-TD group $(P=0.020)$. This analysis was followed up by looking at the five subscales of the AQ. After correcting for multiple comparisons, a main effect of group was found on the attention to detail subscale $\left(F(3,173)=4.146 ; \quad P=0.007 ; \eta^{2}=\right.$ $0.067)$ as a result of the M-FXp $(P=0.010)$ and M-SMS $(P=$ $0.001)$ groups reporting more autistic traits than the M-TD group, and also on the social subscale $\left(F(3,173)=4.254 ; P=0.006 ; \eta^{2}=\right.$ $0.069)$ as a result of the M-ASD group reporting more autistic traits than the M-TD $(P=0.003)$ and M-SMS $(P=0.008)$ groups.

The groups did not differ in the number of mothers reporting autistic traits above the AQ cut-off of 32 for autism $\left(\chi^{2}(3)=6.58 ; P=0.087\right.$; $\left.\eta^{2}=0.036\right)$ as the vast majority of mothers did not report such high levels of autistic traits. However, on taking a cut-off of 20 (indicative of significant autistic traits $\left.{ }^{23}\right)$, the groups did differ $\left(\chi^{2}(3)=15.99\right.$, $P=0.001 ; \eta^{2}=0.088$ ), with more individuals from the M-FXp group $(45 \%, n=23)$ scoring above the cut-off than the M-TD $(14 \%, n=6$, $P=0.001)$ or M-SMS $(11 \%, n=3, P=0.002)$ groups. The M-ASD group lay midway between these groups $(29 \%, n=17)$.

\section{Mental health and parental stress}

A significant group difference was identified on the HADS total score $\left(F(3,167)=7.270 ; P<0.001 ; \eta^{2}=0.116\right)$, as a result of the M-ASD $(P=0.001)$ and M-SMS $(P<0.001)$ groups reporting

Table 2 Study 2 participant characteristics: chronological age, IQ, education and household income

\begin{tabular}{|c|c|c|c|c|}
\hline & $\begin{array}{c}\text { M-FXp group } \\
(n=51)\end{array}$ & $\begin{array}{c}\text { M-TD group } \\
(n=44)\end{array}$ & $\begin{array}{c}\text { NM-FXp group } \\
(n=17)\end{array}$ & $\begin{array}{l}\text { NM-TD group } \\
\quad(n=28)\end{array}$ \\
\hline Age, years: mean (s.d.) & $43(5.8)$ & $40(4.9)$ & $32(9.2)$ & $31(6.8)$ \\
\hline $\mathrm{IQ}^{\mathrm{a}}$ mean (s.d.) & $116(18.1)$ & $121(15.4)$ & $114(26.7)$ & $123(19.6)$ \\
\hline Education, \% higher education ( $n$ ) & $59(30)$ & $91(40)$ & $24(4)$ & $64(18)$ \\
\hline Household income, $\%$ above $£ 45000$ per annum (n) & $46(21)$ & $78(32)$ & $39(5)$ & $19(5)$ \\
\hline \multicolumn{5}{|c|}{$\begin{array}{l}\text { M-FXp, mothers of children with fragile-X syndrome, with the fragile-x permutation (FX-p) themselves; M-TD, mothers of typically developing children; NM-FXp, non-mothers with the FX-p; } \\
\text { NM-TD, typically developed non-mothers. } \\
\text { a. Missing IQ data: } n=5 \text { M-NT group. } \\
\text { b. Household income not declared/missing: } n=5 \text { M-FXp group, } n=3 \text { M-NT group, } n=4 \text { NM-FXp group and } n=2 \text { NM-TD group. }\end{array}$} \\
\hline
\end{tabular}


Table 3 Study 1 group scores on Autism Spectrum Quotient (AQ), Hospital Anxiety and Depression Scale (HADS), Questionnaire on Resources and Stress Friedrich short form (QRS-F), Positive Affect Scale (PAS) and Positive Gain Scale (PGS)

\begin{tabular}{|c|c|c|c|c|}
\hline & $\begin{array}{c}\text { M-FXp group } \\
\quad(n=51)\end{array}$ & $\begin{array}{l}\text { M-ASD group } \\
\quad(n=59)\end{array}$ & $\begin{array}{l}\text { M-SMS group } \\
\quad(n=27)\end{array}$ & $\begin{array}{l}\text { M-TD group } \\
\quad(n=44)\end{array}$ \\
\hline \multicolumn{5}{|l|}{$\mathrm{AQ}$} \\
\hline Total score, mean (s.d.) & $18.65(8.92)$ & $16.92(10.64)$ & $14.70(6.66)$ & $11.32(6.32)$ \\
\hline Social, mean (s.d.) & $3.35(2.67)$ & $3.46(2.78)$ & $2.00(1.88)$ & $1.57(1.87)$ \\
\hline Attention switching, mean (s.d.) & $4.63(2.76)$ & $4.10(2.58)$ & $3.26(2.16)$ & $3.20(1.69)$ \\
\hline Attention to detail, mean (s.d.) & $4.86(2.14)$ & $4.34(2.26)$ & $5.33(1.98)$ & $3.32(2.22)$ \\
\hline Communication, mean (s.d.) & $2.88(2.53)$ & $2.68(2.72)$ & 1.89 (1.95) & $1.59(1.80)$ \\
\hline Imagination, mean (s.d.) & $2.92(2.11)$ & $2.34(2.13)$ & $2.22(1.50)$ & $1.64(1.60)$ \\
\hline \% above autism cut-off (cut-off 32) (n) & $6(3)$ & $12(7)$ & $4(1)$ & $0(0)$ \\
\hline \multicolumn{5}{|l|}{$\mathrm{HADS}^{\mathrm{a}}$ mean (s.d.) } \\
\hline Total score & $14.10(6.84)$ & $15.09(7.44)$ & $17.38(6.13)$ & $9.59(5.21)$ \\
\hline Anxiety & $9.43(4.37)$ & $9.35(4.34)$ & 9.88 (3.33) & $6.54(3.31)$ \\
\hline Depression & $4.67(3.20)$ & $5.74(3.98)$ & $7.50(3.68)$ & $3.05(2.67)$ \\
\hline \multicolumn{5}{|l|}{ HADS, anxiety cut-off } \\
\hline$\%$ Normal $(n)$ & $37(19)$ & $37(21)$ & $35(9)$ & $66(27)$ \\
\hline$\%$ Mild $(n)$ & $20(10)$ & $23(13)$ & $23(6)$ & $17(7)$ \\
\hline \% Moderate $(n)$ & $31(16)$ & $23(13)$ & $39(10)$ & $17(7)$ \\
\hline$\%$ Severe $(n)$ & $12(6)$ & $17(10)$ & $4(1)$ & $0(0)$ \\
\hline \multicolumn{5}{|l|}{ HADS, depression cut-off } \\
\hline$\%$ Normal $(n)$ & $80(41)$ & $70(40)$ & $62(16)$ & $90(37)$ \\
\hline$\%$ Mild $(n)$ & $14(7)$ & $23(13)$ & $19(5)$ & $10(4)$ \\
\hline$\%$ Moderate $(n)$ & 6 (3) & $4(2)$ & $19(5)$ & $0(0)$ \\
\hline$\%$ Severe $(n)$ & $0(0)$ & $4(2)$ & $0(0)$ & $0(0)$ \\
\hline QRS-F, ${ }^{b}$ total score: mean (s.d.) & $4.29(2.14)$ & $4.44(1.72)$ & $4.81(2.28)$ & $1.32(1.37)$ \\
\hline $\mathrm{PAS}^{\mathrm{C}}{ }^{\mathrm{C}}$ total score: mean (s.d.) & $15.82(4.32)$ & $15.73(4.19)$ & $15.15(3.86)$ & $18.12(3.32)$ \\
\hline PGS, ${ }^{d}$ total score: mean (s.d.) & $21.39(4.90)$ & $20.81(4.31)$ & 23.08 (3.94) & - \\
\hline \multicolumn{5}{|c|}{$\begin{array}{l}\text { M-FXp, mothers of children with fragile-x syndrome, with the fragile-x permutation themselves; M-ASD, mothers of autistic children; M-SMS, mothers of children with Smith-Magenis } \\
\text { syndrome; M-TD, mothers of typically developing children. } \\
\text { a. Missing HADS data: } n=2 \text { M-ASD group, } n=1 \text { M-SMS group, } n=3 \text { M-TD group. } \\
\text { b. Missing QRS-F data: } n=2 \text { M-ASD group, } n=1 \text { M-SMS group, } n=3 \text { M-TD group. } \\
\text { c. Missing PAS data: } n=2 \text { M-ASD group, } n=1 \text { M-SMS group, } n=3 \text { M-TD group. } \\
\text { d. Missing PGS data: } n=4 \text { M-ASD group, } n=1 \text { M-SMS group. }\end{array}$} \\
\hline
\end{tabular}

significantly more mental health symptoms than the M-TD group. A trend towards more mental health symptoms in the M-FXp group than the M-TD group was also found $(P=0.013)$. A group effect was also present in the anxiety subscale $(F(3,167)=4.751 ; P=0.003$; $\left.\eta^{2}=0.079\right)$, as a result of all three groups of mothers of children with neurodevelopmental disorders reporting higher rates of anxiety symptoms (all $P$-values $\leq 0.003$ ), and the depression subscale $\left(F(3,167)=8.868 ; P<0.001 ; \eta^{2}=0.137\right)$, as a result of the M-ASD group $(P=0.002)$ reporting more depression symptoms than the $\mathrm{M}-\mathrm{TD}$ group and the M-SMS group reporting more depression symptoms than the M-TD $(P<0.001)$ and M-FXp groups $(P<0.001)$.

The groups differed in QRS-F total score $(F(3,167)=26.406$; $\left.P<0.001 ; \eta^{2}=0.322\right)$; mothers in all three clinical groups reported higher levels of stress than the M-TD group (all $P$-values $<0.001$ ). There was also a group difference on the PAS $(F(3,167)=2.675$; $\left.P=0.049 ; \eta^{2}=0.046\right)$. Post hoc pairwise comparisons showed a trend towards reduced positive affect in the M-ASD $(P=0.016)$ and M-SMS $(P=0.016)$ groups compared with the M-TD group. The PGS did not produce a significant main effect of group (data only from the three clinical groups; $F(2,125)=1.322 ; P=0.270 ; \eta^{2}$ $=0.021$ ), indicating that all three groups could identify similar degrees of positive experience from parenting a child with a neurodevelopmental disorder.

Association between autistic traits, mental health and parental stress To investigate the associations between the main variables of interest and the influence of age, education level and income on these variables, we asked whether autistic traits, parenting stress and positive affect could explain the variance in mental health symptoms in each of the individual groups, over and above the effects of group differences in age, education level and household income. Here, we grouped anxiety and depression together as these scales were highly correlated in all four groups (all $r \mathrm{~s}>0.52, P$-values $<0.003$ ). Using stepwise multiple linear regression, we found that AQ total score was the best predictor of HADS total score in both the M-FXp $(\beta=0.528 ; P<0.001)$ and M-ASD groups $(\beta=0.502 ; P<$ 0.001 ), accounting for $28 \%$ and $25 \%$ of the variance, respectively. The final model for the M-FXp group $\left(R^{2}=0.355 ; F(2,48)=\right.$ 13.195; $P<0.001)$ included the AQ $(\beta=0.358 ; P=0.012)$ and the PAS $(\beta=-0.324 ; P=0.022)$; likewise, for the M-ASD group the final model $\left(R^{2}=0.345 ; F(2,54)=14.195 ; P<0.001\right)$ included the AQ $(\beta=0.433 ; P<0.001)$ and the PAS $(\beta=-0.313 ; P=0.008)$.

In contrast, the best predictor of HADS total score for the M-SMS group was the PAS ( $\beta=-0.618 ; P=0.001)$, accounting for $38 \%$ of the variance. The final model for this group $\left(R^{2}=0.482\right.$; $F(2,23)=10.684 ; P<0.001)$ included the PAS $(\beta=-0.566 ; P=$ $0.001)$ and the AQ $(\beta=0.320 ; P=0.047)$. For the M-TD group, the best predictor of HADS total was the QRS-F $(\beta=0.524 ; P<$ $0.001)$, accounting for $27 \%$ of the variance. The final model for this group $\left(R^{2}=0.423 ; F(3,37)=9.051 ; P<0.001\right)$ included the QRS-F $(\beta=0.471 ; P=0.001)$, the AQ $(\beta=0.301 ; P=0.027)$ and age $(\beta=0.262 ; P=0.044)$.

\section{Study 2 results}

Although the data were not normally distributed, non-parametric approaches cannot accommodate this two $\times$ two design. Furthermore, as in study 1, parametric tests allowed us to control for participant characteristics that significantly differed between the groups (age, education and household income). Consequently, data were analysed using a two-way ANCOVA, which is reported to be robust enough to compare small samples of non-normally distributed data. ${ }^{29}$ An alpha level of 0.05 was used for analysis of main 
effects and interactions in relation to total scores and an alpha level of 0.01 was used for analysis of subscale scores to adjust for multiple comparisons. Table 4 describes group scores and proportion meeting cut-off scores on measures of autistic traits, anxiety, depression and positive affect.

\section{Autistic traits in study 2}

A two-way ANCOVA revealed a main effect of premutation status $\left(F(1,132)=8.432 ; P=0.004 ; \eta^{2}=0.060\right)$ with higher AQ scores in women with FX-p relative to the typically developing women, but no main effect of motherhood $\left(F(1,132)=0.397 ; P=0.530 ; \eta^{2}=\right.$ $0.003)$. The interaction was not significant $(F(1,132)=1.273 ; P=$ $\left.0.1261 ; \eta^{2}=0.010\right)$. Analysis of AQ subscale scores revealed a main effect of premutation status for the social subscale $(F(1,132)=$ 6.776; $\left.P=0.010 ; \eta^{2}=0.049\right)$ with higher scores in women with the FX-p relative to typically developing women. There was no significant main effect of premutation status or motherhood for any of the other subscales. However, it is worth noting that the main effect of premutation status was borderline significant for the communication $\left(F(1,132)=5.540 ; \quad P=0.020 ; \eta^{2}=0.040\right)$ and attention switching $\left(F(1,132)=6.186 ; \quad P=0.014 ; \eta^{2}=0.045\right)$ subscales, and for the imagination subscale the main effect of motherhood was borderline significant $\left(F(1,132)=4.474 ; P=0.036 ; \eta^{2}=0.033\right)$.

\section{Mental health}

Analysis of scores on the HADS demonstrated a main effect of premutation status $\left(F(1,129)=6.418 ; P=012 ; \eta^{2}=0.047\right)$ with higher scores in women with the premutation but no main effect of motherhood $\left(F(1,129)=1.170 ; P=0.281 ; \eta^{2}=0.009\right)$. Specifically, scores on the anxiety subscale of the HADS were significantly higher in women with the premutation $(F(1,129)=7.479 ; P=$ $\left.0.007 ; \eta^{2}=0.055\right)$. There was no significant main effect of premutation status $\left(F(1,129)=2.680 ; P=0.104 ; \eta^{2}=0.020\right)$ or motherhood $\left(F(1,129)=3.812 ; P=0.053 ; \eta^{2}=0.029\right)$ on the PAS scores.

\section{Association between number of CGG repeats and autistic traits and mental health}

Data regarding number of CGG repeats was available for 24 of the total sample of participants with the FX-p (mothers and nonmothers combined). There were no significant correlations between the number of CGG repeats and scores on the AQ or HADS.

\section{Discussion}

Research that focuses on women with the FX-p has been significantly underrepresented within the field of behavioural phenotypes. Although there has been some research to indicate areas of physical difference in this population, studies into the behavioural and emotional characteristics that might have an impact on day-to-day functioning, family stress and adjustment have been somewhat limited. We report on two studies in which we evaluated the broader autism phenotype and characteristics of mental health and well-being in women with the FX-p. In study 1 we considered these characteristics in the context of caring for a child with a neurodevelopmental disorder. In study 2 we evaluated more specifically, the presence of the FX-p and maternal status as putative risk markers for the presentation of the broader autism phenotype and mental health challenges.

\section{Main findings and comparison with findings from other studies}

Consistent with previous research, ${ }^{6,9}$ the findings from study 1 indicated that mothers with the FX-p showed significantly higher levels of autistic traits relative to mothers of typically developing children. Specifically, autistic traits within the area of attention to detail was elevated in this group. Mothers of autistic children also reported more autistic traits than mothers of typically developing children with borderline significance $(P=0.020)$. This pattern of findings was also reflected at the level of cut-off scores thought to be indicative of 'significant autistic traits', ${ }^{20}$ with more mothers of children with FXS $(45 \%, n=23)$ meeting this cut-off relative to the M-TD group $(14 \%, n=6)$ and mothers of children with a non-heritable neurodevelopmental disorder associated with significant challenging behaviour: Smith-Magenis syndrome $(11 \%, n=3)$. This pattern of findings indicates that mothers of children with FXS who have the FX-p are at significantly greater risk for autistic traits relative to mothers of typically developing children and present a similar level of risk to that reported in mothers of autistic children in the current and in previous studies. ${ }^{21}$

Findings relating to mental health and parental stress were also consistent with previous literature. ${ }^{5-11,17,18}$ Anxiety, depression and indicators of parental stress were significantly higher in all three groups of mothers of children with neurodevelopmental disorders relative to mothers of typically developing children. Mothers of children with Smith-Magenis syndrome were at particularly significant risk of experiencing severe depression relative to mothers of children with FXS or autistic children. The fact that in all groups there is evidence of high rates of parental stress and mental health challenges, whereas only the mothers of children with FXS and autistic children show evidence of increased risk for autistic traits, suggests that the presence of these traits is not entirely mediated by the stress of caring for a child with a significant level of need, and is more likely to be a population-specific characteristic. The two $x$ two design of study 2 enabled a more precise evaluation of the relative effect of motherhood versus the FX-p.

Consistent with the findings from study 1 , study 2 demonstrated a significant main effect of premutation status that did not interact with motherhood, whereby women with the FX-p, regardless of maternal status, showed significantly increased levels of autistic traits and anxiety relative to women without the FX-p. Consistent with findings from Gossett and colleagues ${ }^{12}$ and Schneider and colleagues ${ }^{13}$ who also report increased risk of autistic traits, depression and obsessive-compulsive symptoms in women with the FX-p who did not have children; these results indicate that the presence of the FX-p confers significant risk for autistic traits and mental health challenges across this population. This risk is not systematically increased by having caring responsibilities for a child or children with a neurodevelopmental disability.

\section{Interpretation of our findings}

The findings demonstrate the presence of a subtle and specific behavioural phenotype associated with the FX-p that cannot be fully accounted for by factors associated with parental stress and adjustment. Rather, the findings suggest an increased risk for certain psychological and behavioural characteristics that, for some individuals, present a significant day-to-day challenge. These characteristics, particularly anxiety, may be exacerbated by the stress of caring for a child or children with significant need but are not solely accounted for by such factors. The findings have implications for decision-making pathways regarding testing and diagnosis of siblings and relatives of individuals with the full FXS, who are at risk for the FX-p. Early recognition and identification of these challenges may be important for providing preventative and early intervention and support for women with the FX-p and their families.

Given the heightened prevalence of autism in individuals with the full FXS, the finding of increased risk for broader autism 
Table 4 Study 2 group scores on Autism Spectrum Quotient (AQ), Hospital Anxiety and Depression Scale (HADS) and Positive Affect Scale (PAS)

\begin{tabular}{|c|c|c|c|c|}
\hline & $\begin{array}{c}\text { M-FXp group } \\
\quad(n=51)\end{array}$ & $\begin{array}{l}\text { M-TD group } \\
(n=44)\end{array}$ & $\begin{array}{l}\text { NM-FXp group } \\
\quad(n=17)\end{array}$ & $\begin{array}{l}\text { NM-TD group } \\
\quad(n=28)\end{array}$ \\
\hline \multicolumn{5}{|l|}{$A Q$} \\
\hline Total score, mean (s.d.) & $18.65(8.92)$ & $11.32(6.32)$ & $20.94(7.06)$ & $17.54(8.42)$ \\
\hline Social, mean (s.d.) & $3.35(2.67)$ & $1.57(1.87)$ & $4.00(2.78)$ & $2.71(2.64)$ \\
\hline Attention switching, mean (s.d.) & $4.63(2.76)$ & $3.20(1.69)$ & $5.71(2.05)$ & $4.54(2.40)$ \\
\hline Attention to detail, mean (s.d.) & $4.86(2.14)$ & $3.32(2.22)$ & $5.23(2.08)$ & $5.57(2.25)$ \\
\hline Communication, mean (s.d.) & $2.88(2.53)$ & $1.59(1.80)$ & $3.59(1.97)$ & $2.57(2.54)$ \\
\hline Imagination, mean (s.d.) & $2.92(2.11)$ & $1.64(1.60)$ & $2.41(1.94)$ & $2.14(1.69)$ \\
\hline \% above autism cut-off (cut-off 32) (n) & $6(3)$ & $0(0)$ & $12(2)$ & $14(4)$ \\
\hline \multicolumn{5}{|l|}{ HADS, ${ }^{a}$ mean (s.d.) } \\
\hline Total score & $14.10(6.84)$ & $9.59(5.21)$ & $14.76(5.95)$ & $13.39(5.66)$ \\
\hline Anxiety & $9.43(4.37)$ & 6.54 (3.31) & $10.24(4.29)$ & $8.93(3.89)$ \\
\hline Depression & $4.67(3.20)$ & $3.05(2.67)$ & $4.53(2.62)$ & $4.46(2.62)$ \\
\hline \multicolumn{5}{|l|}{ HADS, anxiety cut-off } \\
\hline$\%$ Normal $(n)$ & $37(19)$ & $61(27)$ & $29(5)$ & $36(10)$ \\
\hline$\%$ Mild $(n)$ & $20(10)$ & $16(7)$ & $29(5)$ & $29(8)$ \\
\hline \% Moderate $(n)$ & $31(16)$ & $16(7)$ & $24(4)$ & $36(10)$ \\
\hline$\%$ Severe $(n)$ & $12(6)$ & $0(0)$ & $18(3)$ & $0(0)$ \\
\hline \multicolumn{5}{|l|}{ HADS, depression cut-off } \\
\hline$\%$ Normal $(n)$ & $80(41)$ & $84(37)$ & $88(15)$ & $82(23)$ \\
\hline$\%$ Mild $(n)$ & $14(7)$ & $9(4)$ & $12(2)$ & $14(4)$ \\
\hline \% Moderate $(n)$ & $6(3)$ & $0(0)$ & $0(0)$ & $4(1)$ \\
\hline$\%$ Severe $(n)$ & $0(1)$ & $0(0)$ & $0(0)$ & $0(0)$ \\
\hline PAS, ${ }^{b}$ total score & $15.82(4.32)$ & $18.12(3.32)$ & $16.58(5.08)$ & $17.68(5.05)$ \\
\hline $\begin{array}{l}\text { M-FXp, mothers of children with fragile-x syndrome, } v \\
\text { NM-TD, typically developed non-mothers. } \\
\text { a. Missing HADS data: } n=3 \text { M-TD group. } \\
\text { b. Missing PAS data: } n=3 \text { M-TD group. }\end{array}$ & permutation ( $F X$ & n-TD, mothers o & & with the FX-p; \\
\hline
\end{tabular}

phenotype traits in mothers with the FX-p, as well as in women with the FX-p without children, indicates a pattern of autism heritability that appears to mirror that observed in the wider autism population. Although the majority of cases of autism are thought to result from the interaction of multiple common genetic variants rather than a single rare mutation as in $\mathrm{FXS},{ }^{30}$ heritability estimates in autism are higher than for any other medical or psychiatric disorder. ${ }^{25}$ These traits are thought to be passed on by intergenerational transmission, indeed, the degree of parental autistic traits has been found to predict the degree of child autistic symptoms. ${ }^{31}$ This similarity has implications for our understanding of the aetiological pathways that may underpin the pattern of heritability of autistic traits more broadly and requires further investigation.

The profile of predictive factors for mental health problems differed across participant groups. In mothers with the FX-p and mothers of autistic children, the presence of autistic traits was the strongest predictor of their own mental health outcome. In contrast, the strongest predictor of mental health outcome in mothers of children with Smith-Magenis syndrome was positive affect and in mothers of typically developing children, the strongest predictor was coping skills. This emphasises the detrimental effect that elevated autistic traits can have on mental health, possibly the consequence of masking autistic traits in order to fit in. ${ }^{32}$

\section{Limitations}

The findings should be considered in the context of several study limitations. First, the studies relied on self-report data regarding the premutation status of participants and the diagnostic status of participant's children. However, all participants were asked to provide detailed information regarding their diagnostic status (when, where and by whom a diagnosis was made and whether a blood test was carried out). These additional questions provided greater certainty of diagnostic status and enabled us to exclude individuals who had not received a diagnosis via the most appropriate route or from an appropriate clinician. The reliance on self-report data is a broader limitation of the study. Although some studies have evaluated these characteristics in greater detail using observational methods, ${ }^{13}$ further direct studies are required in order to describe more accurately the behavioural phenotype associated with the FX-p in women.

The small sample size of the NM-FXp $(n=17)$ group is also a limitation of the study. However, this group of individuals is incredibly difficult to identify given that most women are only made aware of their premutation status after having a child with the full syndrome or premutation. Furthermore, the sample size of the NMFXp group is broadly in line with other studies that have recruited women with the FX-p who do not have children (for example Schneider and colleagues $n=22^{13}$ ). Although the sample size of the M-FXp group is larger $(n=51)$ it is still relatively small and this is likely to have limited statistical power (reflected in several borderline significant findings). Further, given that the Fragile $\mathrm{X}$ Society, UK advertised the study to 700 individuals in their membership, the limited response rate in the current study suggests that the sample may not be representative of the wider population of mothers with the FX-p. Further studies with larger sample sizes are needed to overcome these challenges.

\section{Implications}

In conclusion, our study findings indicate that women with the FX-p show significantly increased risk for autistic traits and anxiety. This risk is specific to the presence of the FX-p and is not explained by maternal status or the stress of caring for a child or children with a neurodevelopmental disorder. These results strongly support the need for recognition of a behavioural and cognitive phenotype for women with the FX-p and support the newly proposed term of fragile-X-associated neuropsychiatric conditions. ${ }^{15,16}$ Early recognition and identification of these challenges will be important for providing appropriate levels of support for women with the FX-p and their families. 
Sarah J. White, Institute of Cognitive Neuroscience, University College London, UK: Denise Gerber, Faculty of Medicine, University of Chile, Chile; Romina D. Sanchez Hernandez, Institute of Cognitive Neuroscience, University College London, UK; Anthonia Efiannayi, Institute of Cognitive Neuroscience, University College London, UK; Ishita Chowdhury (D), Institute of Cognitive Neuroscience, University College ondon, UK: Hannah Partington, Institute of Cognitive Neuroscience University College London, UK; Joanna F. Moss $(\mathbb{D}$, School of Psychology, University of Surrey, UK

Correspondence: Joanna F. Moss. Email: j.moss@surrey.ac.uk

First received 31 May 2020, final revision 7 Oct 2020, accepted 16 Oct 2020

\section{Data availability}

The data that support the findings of this study are available from the corresponding author, J.F.M., upon reasonable request.

\section{Acknowledgements}

We are grateful to the Fragile $X$ Society, National Autistic Society and the Smith-Magenis syndrome Foundation, UK for their support with recruitment and to all the women who participated in this study. Thanks also to Bethany Webster for her help with editing and formatting the tables and manuscript for publication.

\section{Author contributions}

S.J.W. formulated the research questions, contributed to the design of the study, supervised data collection and analysis and edited the final manuscript. D.G. set up the online survey and collected data for the M-FXP, M-ASD and M-TD groups, conducted preliminary analysis and contributed to an early version of the manuscript. R.D.S.H. collected data for the NMFXp and M-SMS groups, conducted preliminary analysis and contributed to an early version of the manuscript. A.E. collected data for the NM-TD group, conducted preliminary analysis and contributed towards an early version of the manuscript. I.C. processed the data for all participant groups and conducted preliminary analysis. H.P. ran statistical re-analysis following initicial review and modified the original manuscript. J.F.M. formulated the research questions, had oversight over the design of the study, supervised data collection and analysis and wrote the final manuscript.

\section{Funding}

This research was funded by the Experimental Psychology Society, Cerebra and the Royal Society (DH150167).

\section{Declaration of interest}

\section{None.}

\section{References}

1 McDuffie A, Thurman AJ, Hagerman RJ, Abbeduto L. Symptoms of autism in males with fragile $X$ syndrome: a comparison to nonsyndromic ASD using current ADI-R scores. J Autism Dev Disord 2015; 45: 1925-37.

2 Talisa VB, Boyle L, Crafa D, Kaufmann WE. Autism and anxiety in males with fragile $X$ syndrome: an exploratory analysis of neurobehavioral profiles from a parent survey. Am J Med Genet A 2014; 164: 1198-203.

3 Seltzer MM, Baker MW, Hong J, Maenner M, Greenberg J, Mandel D. Prevalence of CGG expansions of the FMR1 gene in a US population-based sample. Am J Med Genet B Neuropsychiatr Genet 2012; 159: 589-97.

4 Grigsby J, Cornish K, Hocking D, Kraan C, Olichney JM, Rivera SM, et al. The cognitive neuropsychological phenotype of carriers of the FMR1 premutation. J Neurodev Disord 2014; 6: 28.

5 Kraan CM, Hocking DR, Bradshaw JL, Fielding J, Cohen J, Georgiou-Karistianis $\mathrm{N}$, et al. Neurobehavioural evidence for the involvement of the FMR1 gene in female carriers of fragile X syndrome. Neurosci Biobehav Rev 2013; 37: 522-47.

6 Clifford S, Dissanayake C, Bui QM, Huggins R, Taylor AK, Loesch DZ. Autism spectrum phenotype in males and females with fragile $X$ full mutation and premutation. J Autism Dev Disord 2007; 37: 738-47.

7 Bourgeois JA, Cogswell JB, Hessl D, Zhang L, Ono MY, Tassone F, et al. Cognitive, anxiety and mood disorders in the fragile $\mathrm{X}$-associated tremor/ ataxia syndrome. Gen Hosp Psychiatry 2007; 29: 349-56.

8 Kenna HA, Tartter M, Hall SS, Lightbody AA, Nguyen Q, de los Angeles CP, et al. High rates of comorbid depressive and anxiety disorders among women with premutation of the FMR1 gene. Am J Med Genet B Neuropsychiatr Genet 2013; 162: 872-8.
9 Losh M, Klusek J, Martin GE, Sideris J, Parlier M, Piven J. Defining genetically meaningful language and personality traits in relatives of individuals with fragile $X$ syndrome and relatives of individuals with autism. Am J Med Genet B Neuropsychiatr Genet 2012; 159: 660-8.

10 Movaghar A, Page D, Brilliant M, Baker MW, Greenberg J, Hong J, et al. Datadriven phenotype discovery of FMR1 premutation carriers in a populationbased sample. Sci Adv 2019; 15: 7195.

11 Roberts JE, Bailey DB Jr, Mankowski J, Ford A, Sideris J, Weisenfeld LA, et al. Mood and anxiety disorders in females with the FMR1 premutation. Am J Med Genet B Neuropsychiatr Genet 2009; 150: 130-9.

12 Gossett A, Sansone S, Schneider A, Johnston C, Hagerman R, Tassone F, et al. Psychiatric disorders among women with the fragile $X$ premutation without children affected by fragile $X$ syndrome. Am J Med Genet B Neuropsychiatr Genet 2016; 171: 1139-47.

13 Schneider A, Johnston C, Tassone F, Sansone S, Hagerman RJ, Ferrer E, et al. Broad autism spectrum and obsessive-compulsive symptoms in adults with the fragile X premutation. Clin Neuropsychol 2016; 30: 929-43.

14 Hagerman RJ, Protic D, Rajaratnam A, Salcedo-Arellano MJ, Aydin EY Schneider A. Fragile X-associated neuropsychiatric disorders (FXAND). Front Psychiatry 2018; 9: 564.

15 Johnson K, Herring J, Richstein J. Fragile X premutation associated conditions (FXPAC). Front Pediatrics 2020; 8: 266

16 Totsika V, Hastings RP, Emerson E, Lancaster GA, Berridge DM. A populationbased investigation of behavioural and emotional problems and maternal mental health: associations with autism spectrum disorder and intellectual disability. J Child Psychol Psychiatry 2011; 52: 91-9.

17 Abbeduto L, Seltzer MM, Shattuck P, Krauss MW, Orsmond G, Murphy MM Psychological well-being and coping in mothers of youths with autism, Down syndrome, or fragile X syndrome. Am J Ment Retard 2004; 109 237-54.

18 Johnston C, Hessl D, Blasey C, Eliez S, Erba H, Dyer-Friedman J, et al. Factors associated with parenting stress in mothers of children with fragile $X$ syndrome. J Dev Behav Pediatr 2003; 24: 267-75.

19 Limesurvey GmbH. LimeSurvey: An Open Source Survey Tool. LimeSurvey $\mathrm{GmbH}$, no date (http://www.limesurvey.org).

20 Baron-Cohen S, Wheelwright S, Skinner R, Martin J, Clubley E. The autismspectrum quotient (AQ): evidence from asperger syndrome/high-functioning autism, males and females, scientists and mathematicians. J Autism Dev Disord 2001; 31: 5-17.

21 Wheelwright S, Auyeung B, Allison C, Baron-Cohen S. Defining the broader medium and narrow autism phenotype among parents using the Autism Spectrum Quotient (AQ). Mol Autism 2010; 1: 10

22 Zigmond AS, Snaith RP. The Hospital Anxiety and Depression Scale. Acta Psychiatr Scand 1983; 67: 361-70.

23 Griffith GM, Hastings RP, Petalas MA, Lloyd TJ. Mothers' expressed emotion towards children with autism spectrum disorder and their siblings. J Intellect Disabil Res 2015; 59: 580-7.

24 Friedrich WN, Greenberg MT, Crnic K. A short-form of the Questionnaire on Resources and Stress. Am J Ment Defic 1983; 88: 41-8.

25 Tick B, Bolton P, Happé F, Rutter M, Rijsdijk F. Heritability of autism spectrum disorders: a meta-analysis of twin studies. J Child Psychol Psychiatry 2016; 57: 585-95

26 Pit-ten Cate IM. Family Adjustment to Disability and Chronic IIIness in Children (Doctoral Dissertation, University of Southampton, UK). ProQuest; UMI Dissertations Publishing, 2003.

27 Watson D, Clark LA, Tellegen AJ. Development and validation of brief measures of positive and negative affect: the PANAS scales. Pers Soc Psychol 1988; 54: 1063-70.

28 Cattell RB, Cattell AK. Measuring Intelligence with the Culture Fair Tests. Institute for Personality and Ability Testing, 1960

29 Ito PK. 7 robustness of ANOVA and MANOVA test procedures. In Handbook of Statistics Volume 1: (ed. Krishnaiah P.R.): 199-236. Elsevier, 1980.

30 Lai JK, Sobala-Drozdowski M, Zhou L, Doering LC, Faure PA, Foster JA. Temporal and spectral differences in the ultrasonic vocalizations of fragile $X$ knock out mice during postnatal development. Behav Brain Res 2014; 259: 119-30

31 Lyall K, Schmidt RJ, Hertz-Picciotto I. Maternal lifestyle and environmental risk factors for autism spectrum disorders. Int J Epidemiol 2014; 43: 443-64.

32 Livingston LA, Happé F. Conceptualising compensation in neurodevelopmental disorders: reflections from autism spectrum disorder. Neurosci Biobehav Rev 2017; 80: 729-42. 